\title{
Strengthening the Cost Effectiveness of Medical Countermeasure Development Against Rare Biological Threats: The Ebola Outbreak
}

\author{
Mark Lawrence Johnson ${ }^{1,2}$ (1) Jean Belin ${ }^{3,4} \cdot$ Frederic Dorandeu $^{5,6}$ • \\ Marianne Guille ${ }^{2}$
}

Published online: 31 October 2017

(C) Springer International Publishing AG 2017

\begin{abstract}
Some chemical, biological, radiological, and nuclear agents, whether naturally, accidentally, or intentionally released, can be very damaging and pose a high risk to national security, owing to their potential for economic and social disruption. Efficacious pharmaceutical research and development could protect populations against such agents via new prophylactic drugs and vaccines or post-exposure treatment with antidotes and antimicrobials. However, because of the unpredictable nature of when, if ever, the health risks of specific chemical, biological, radiological, and nuclear agents might be realized, the development of medical countermeasures against these agents carries less promise of free market rewards to entice investment, and thus this development necessitates public funding or incentives. In terms of defining the level and targets of such public funding, the potential economic impact of any realized threat must be determined. This article first examines the specific components of market failure-research and development efforts vs. market rewards-associated with medical countermeasures against
\end{abstract}

Mark Lawrence Johnson

johnson@mjlconsulting.eu

1 MJ Lawrence Consulting, Postfach 7106 60, Munich 81456, Germany

2 Université Panthéon-Assas, LEMMA and Labex MME-DII, 4 Rue Blaise Desgoffe, 75006 Paris, France

3 University Bordeaux (Gretha - UMR CNRS 5113), 16 Avenue Léon Duguit, 33608 Pessac Cedex, France

4 Armament and Defence Economy Chair (Cercle des Partenaires de l'IHEDN), Paris, France

5 Armed Forces Biomedical Research Institute (IRBA), Brétigny-sur-Orge, France

6 Ecole du Val-de-Grace, Paris, France chemical, biological, radiological, and nuclear agents. Then, the latest natural outbreak of the Ebola virus disease is used as a case study to illustrate the risks that such biological agents can pose to social and economic structures. Rather than addressing risks associated with exposure from terrorist events, this case study highlights the potential to strengthen the case to fund relevant medical countermeasures for naturally occurring diseases with epidemic potential that could also impact Western countries owing to the consequences on their armed forces operating in the area of the outbreak, on trade, or even travelers who may disseminate the disease. To that end, causal factors that led to a lack of medical countermeasures prior to the 2014 outbreak are identified, then opportunities that could have triggered a re-evaluation as a threat worthy of high actionable concern are probed.

\section{Key Points}

Inappropriate preparedness with medical countermeasures against some rare but deadly agents, whether released naturally or intentionally by the human hand, can result in adverse economic consequences far exceeding the costs of strong and comprehensive preparedness initiatives.

Given the difficulty to establish prioritization vs. threat assessment for intentional release, analysis for naturally occurring diseases that have the potential to cause catastrophic impact to society can strengthen the case for funding relevant medical countermeasures. 


\section{Introduction}

In November 2001, the Ministers of Health from several nations (Canada, France, Germany, Italy, Japan, Mexico, UK, and USA) called for concerted global action to strengthen the public health response to the threat of international chemical, biological, radiological, and nuclear (CBRN) terrorism. Hence, the Global Health Security Initiative was born and remains in force. The Global Health Security Initiative has recently restated the increasing importance of its purpose: "The rise in terroristrelated events over the past year has reinforced that our collaborative efforts in response to CBRN threats remain a high priority" [1]. Indeed, there are numerous CBRN agents proficient enough to cause harm to individuals. Some biological agents have the potential to cause catastrophic impact to society despite a low natural prevalence (proportion of individuals in a population at risk who are adversely affected) and incidence (number of new cases of a disease caused by CBRN agents over a given period divided by the population at risk), or may lack a probability of emerging at all without human intervention. The US Centers for Disease Control and Prevention (CDC) have classified such biological agents as "Category A Biological Threats". Examples include those causing anthrax, plague, smallpox, tularaemia, and viral hemorrhagic fevers such as Ebola virus disease (EVD) and all have been militarized in the past [2]. The CDC states these agents pose a high risk to national security as they can be easily disseminated or transmitted person to person, might cause high mortality, with potential for major public health impact, public panic, and social disruption (especially if the 'human hand' is proved to be behind the event) and, as such, require special action for public health preparedness [2].

Medical countermeasures (MedCMs) are defined as either a drug, biological product, or device that prevents, identifies, or treats consequences from exposure to a CBRN agent [3]. To achieve effective MedCMs, research and development $(\mathrm{R} \& \mathrm{D})$ to discover and evaluate a compound against a well-defined therapeutic target is a prerequisite [4]. Assuming successful pharmaceutical R\&D is carried out, populations could be protected via new prophylactic drugs and vaccines or post-exposure treatments, such as antidotes and antimicrobials. Developers and manufacturers of MedCMs, however, are not empowered to address all these threats: the process to develop MedCMs is lengthy, risky, and expensive. Because of the unpredictable nature of when, if ever, the health risks of specific CBRN agents might be realized, the development of MedCMs against these agents carries less promise of free market rewards to entice investment, and thus this development necessitates public funding or incentives. In terms of defining the level and targets of such public funding, the potential economic impact of any realized threat must be determined.

It is important to note that not all MedCMs should necessarily be viewed as suffering from this same challenge. This article focuses on medicinal drugs requiring licensure for their delivery and use. The consequences of low investment in R\&D can be detrimental, as illustrated by the latest natural outbreak of EVD that began in March 2014. Of unprecedented magnitude, this outbreak claimed over 11,000 deaths in Guinea, Liberia, and Sierra Leone as of February 2016 [5]. Clearly, an effective MedCM, in the form of a vaccine or an antiviral, was not available. Protection against such highly dangerous but rarely occurring agents requires appropriate involvement by public authorities so that responsible preparedness plans can be driven. Only through the commitment of adequate government incentives can the industry's vital R\&D resources be engaged. Given the budgetary constraints many governments face, however, priorities must be defined. Moreover, international cooperation is necessary, as the risks increasingly transcend borders, as a result of global travel and exchanges. While current health decision metrics strive to effectively identify and weigh the causal effects of negative health impact relative to each metric, decision making must also take into account cost effectiveness to enable sustainability.

The objective of this article is twofold: (1) to draw some lessons by analyzing the specific economic features that discourage the creation of MedCMs and (2) to suggest possible solutions and recommendations to promote their development. To that end, the next sections first emphasize the 'market failures' (e.g., where market rewards do not balance R\&D effort) impeding the availability of MedCMs. Thereafter, the latest natural outbreak of EVD is used as a case study to illustrate the risks that CBRN agents can pose to social and economic structures. This case study does not address risks associated with exposure to CBRN agents via terrorist or military activity; rather, it highlights the potential to strengthen the case to fund MedCMs for CBRN agents with natural epidemic potential. These can impact Western armed forces operating in the area of the outbreak and pose threats via travelers who may transfer the disease back to their home countries. Through exploring adverse impacts to social and economic structures, causal factors that led to a lack of MedCMs prior to the 2014 outbreak are identified. Then, possible reasons that may have triggered a re-evaluation as a threat worthy of high actionable concern are probed.

\section{Medical Countermeasure Market Failures}

The core concept of a 'market failure' to support the development of MedCMs against CBRN agents is that the risk and cost, both in time and financially, of the $R \& D$ 
process is not adequately balanced by the market rewards that would normally incentivize such activities for other types of pharmaceutical products. This section explores the features of the R\&D process and market mechanisms that fail to incentivize, hence deter industry from developing MedCMs against many CBRN agents.

\subsection{Research and Development Process and Costs}

The fundamental basis of drug R\&D against rare but highly dangerous CBRN agents bears some similarities to drug R\&D targeting conventional diseases. Namely, both typically take about $10-15$ years to progress through the required phases of testing, and both even upon reaching phase I are subject to success rates lower than $21.5 \%$ [7, 8]. Of course, while regular pharmaceuticals follow the preclinical, phase I, II, III, and post-licensure monitoring steps of development, the efficacy of MedCMs cannot be practically or ethically tested on humans in the same manner.

At least three main factors are specific to and can hinder the development of MedCMs against CBRN agents. The first factor is a significant lack of test persons with the relevant disease, even more so than in the case of many orphan diseases. The European Medicines Agency criteria that determine orphan disease status include a life-threatening or chronic debilitating condition for which prevalence of the condition in the European Union is five or fewer persons per 10,000 [6]. However, for diseases caused by some CBRN agents, there are currently no patients (e.g., smallpox since it was declared eradicated). More generally, patients exposed to CBRN agents are rarely available to test the efficacy of MedCMs (and, of course, it is unethical to expose healthy individuals to CBRN agents). As a result, animal studies must be designed and proven relevant to humans. Such studies are highly complex, time consuming, and costly. The second factor that hinders MedCM R\&D is the disadvantages associated with financial dependency on public funding, specifically in terms of delays, flexibility, and ease of use of funds. Medical countermeasure development is often dependent on public funding, which is often not available when needed and can make developing and adhering to a schedule of studies difficult. Delays and disruptions resulting from the inavailability of funds can derail the stability of small companies, even resulting in layoffs. The third factor is the difficulty in fulfilling the particular laboratory conditions that are often required. For ' $\mathrm{B}$ ' agents (among CBRN agents), biological safety level is the level of the bio-containment precautions that must be observed to isolate dangerous agents in an enclosed laboratory facility. The levels of containment range from the lowest biological safety level 1 to level 4 . Given that many 'B' MedCMs target highly dangerous agents, access to biological safety level 3 and 4 laboratories is essential.
However, getting that access can be difficult, resulting in long waiting times and significant costs.

Conversely, R\&D efforts for MedCMs benefit from some more favorable specifics over R\&D for regular pharmaceuticals. For example, as a relevant disease-carrying population is not usually available, late-phase human trials are often not required. In contrast, phase III studies for conventional diseases can be very large and extensive, requiring anywhere from 1000 to 5000 patients to generate statistically significant data on safety and efficacy [7].

Because R\&D initiatives to achieve new MedCMs are the most extensive and transparent in USA, US data are used as the key source to evaluate costs. According to the US Department of Defense, the costs to achieve one successful drug candidate for MedCM are estimated to be approximately US $\$ 850$ million, depending on the type of drug. This estimate represents the total actual cash outlays (or out-of-pocket costs) for the new molecular entity that could be approved and the cost incurred for other weaker or failed drug candidates. However, whereas the US Department of Defense estimate only covers a healthy population (18-60 years of age), the US Human Health Services, whose mandate also covers protection of the pediatric and geriatric populations, estimates an out-of-pocket cost of US \$1.2-1.5 billion [8]. Additional cost factors such as cost of capital (or capitalized expense) must normally be factored in. They represent the 'opportunity cost' of the investment on drug development, including the return on investment (ROI) required by private investors, given the risk taken. Investors will only provide funding if the expected return at least equals that of other opportunities of investment with similar risk. While not applicable to public funding, these additional capitalized costs for private investors can reach almost the same level as the out-ofpocket expenses themselves, almost doubling the estimated costs. Out-of-pocket expenses for conventional diseases have recently been estimated at around US $\$ 1.4$ billion and the total capitalized costs at nearly US $\$ 3$ billion [9].

It is important to note that the real cost of private external funding includes a premium related to the financial condition of firms, the risk of their projects, and the quality of information (notably information asymmetries resulting in moral hazard and adverse selection effects). It is well known now that this premium is important for R\&D projects and leads to significant financial constraints with negative impact on R\&D investment [10]. In the case of MedCMs, this premium is amplified by the uncertainty of the ROI via the free market and the importance of information asymmetries. Financial constraints are particularly severe in cases where firms are dependent on internal and public funding to finance this type of project. Indeed, this is often the case when there is a small number of buyers associated with a high risk and technological content, 
especially in defence R\&D [11]. Correspondingly, R\&D initiatives related to achieving MedCMs face the challenge of attracting large- and medium-sized manufacturers. In addition to $\mathrm{R} \& \mathrm{D}$ costs required, product developers with proven capabilities could potentially miss out on more lucrative market opportunities if they were to invest time and capital in this small and volatile niche market. Hence, opportunity costs alone significantly narrow down the industry partners interested in the sector to smaller biotech companies that have fewer alternatives for development programs [12].

\subsection{Market Demand and Sales}

Governments started to pay attention to the civilian protection against CBRN agents from the anthrax letter terrorist attacks of 2001 in USA. This event stimulated the creation of the Global Health Security Initiative and the Health Security Committee originally set up informally at the request of European Union ministers in 2001 and formalized in 2013. The Health Security Committee is used by the European Commission to coordinate health-security measures across the European Union and to define preparedness by enabling governments to exchange information, evaluate health events, advise health ministers, and to facilitate coordinated crisis response [13]. Nonetheless, only the US Government (with few additional exceptions) seemed to realize that, without incentives, industry could not provide sufficient technology or the availability of relevant MedCMs against particularly dangerous CBRN agents [2]. This results from a low market demand for MedCMs, which are rarely needed in a natural environment without the threat of intentional (or accidental) release of these rare agents. A 'Special Reserve Fund' was appropriated by the US Government for the Department of Homeland Security, including US $\$ 5.6$ billion over 10 years (2004-13) for the development and procurement of MedCMs (drugs, biological products, or devices) that the Human and Health Services Secretary determined to be a priority. Besides enabling acquisition of late-stage MedCMs to be deposited in the stockpile, the BioShield Act of 2004 increased the authority of the National Institutes of Health to accelerate advanced R\&D. Additionally, the US Food and Drug Administration was empowered to authorize the use of unlicensed MedCMs in the event of an emergency $[14,15]$. The BioShield's Reauthorization Act of 2013 authorized up to US $\$ 2.8$ billion for the years 2014-2018 for this purpose [16].

Following R\&D, regulatory authorities determine whether a MedCM is safe for human consumption and effective at protecting against a targeted agent. In the case of applying an animal model, there is not an agreed regulatory pathway and thus regulatory approval is even more uncertain. However, without intervention, marketing authorization alone is, of course, not sufficient to ensure a
ROI; market rewards and incentives for MedCMs versus regular pharmaceuticals differ even more than their respective R\&D process and costs. BioShield funding provided the MedCM market with a purchase volume of roughly US $\$ 3.3$ billion (originally stemming from US $\$ 5.6$ billion). The budgeting from this single exclusive customer allowed for the procurement of 12 MedCMs over 2004-13 [17]. This would be equivalent to an average annual spending level of roughly US $\$ 330$ million. The total purchase volume targeted predominantly MedCMs against anthrax (44\%) and smallpox (33\%), with the remaining $23 \%$ spent on botulinum (14\%), radiological and nuclear (7\%), and nerve agents (2\%). Further global customer purchases remain ambiguous and far less substantial. Additionally, a market with a single or largely dominant buyer, a quasi-monopsony, offers a higher risk to sellers because the sustainability of their revenues is vulnerable to shifting government policy. In the case of developing vaccines, there is the potential 'risk' of eradicating the natural reservoir of a disease and thus dramatically reducing future sales potential, as with the World Health Organization (WHO) smallpox vaccination campaign [19].

\subsection{Business Model Incompatibility}

As an intensely price-sensitive industry, the pharma/biopharmaceutical sector generally responds more quickly to innovation outputs (e.g., market approval and entry) than inputs (investment) because $R \& D$ phases are far longer and riskier than in most other industries. Correspondingly, uncertainty is highest at the time a patent is sought and $R \& D$ initiated as it is unknown whether the patent will ever receive marketing authorization. Even if approval is granted, the question remains whether it can lead to company growth. As opposed to other high-tech industries, such as computers or software, this industry must deal with a higher degree of limited investor knowledge surrounding human biological systems [18]. Should political leaders wish to achieve international availability of MedCMs, they must incentivize industry to supply them. Using existing approaches such as orphan drug programs and direct public $\mathrm{R} \& \mathrm{D}$ funding may contribute to this objective but offsetting the severely limited market demand is a major obstacle. In the absence of an adequate demand-side rationale for MedCMs (enough buyers willing to pay), a supply-side rationale cannot harmonize with mainstream industrial business models. Strong market demand and the highly lucrative market sales offered for drugs that target widespread conventional diseases deflect the major industry's will away from developing MedCMs.

Indeed, global market demand for conventional biopharmaceutical drugs reached roughly US $\$ 140$ billion in 2013, US\$11 billion alone for the top ranking product for 
rheumatoid arthritis [19]. Combined with the conventional pharmaceutical market, total spending is forecasted to reach nearly US $\$ 1.3$ trillion by 2018 , an increase of some $30 \%$ over the 2013 level [20]. An annual return on equity valued at more than 20\% during 1985-2000 [21]. Nonetheless, faced with low R\&D productivity, patent barriers, regulatory scrutiny, and tight healthcare budgets, the strategies needed to sustain growth included external solutions. This vertical disintegration leads to mergers and acquisitions to acquire new products [21]. Thus, 79 mergers and acquisitions took place worldwide between 2008 and 2012, for a total aggregate value of US $\$ 388$ billion [22].

As opposed to a traditional 'productionist' business model, requiring long-term financial commitment over decades by equity investors until a new molecular entity is approved and marketed, speculative funding is short term [23]. This arises from perceived market value generated by the reporting of product development milestones; the latter earmarks when investors can buy or sell company stock. Hence, sustainability of company growth shifts away from product revenues to the value and earnings of stocks [24]. In this financialized business model, stock price management is key. Correspondingly, listed companies have to promote their growth by focusing on opportunities that influence their short- vs- long-term stock prices and thus their return on equity. To create entry and exit milestones for purchasing and selling its stocks or even the company itself and/or maximizing return on equity, financial news about blockbuster opportunities (e.g., popular drugs that generate at least US\$1 billion annually) must be released in a timely fashion to investors. As opposed to companies that merely seek a profitable scenario in a productionist business model, the market forces capable of incentivizing major industry are dominated by financialized characteristics. Consequently, the MedCM market is deemed as merely a safe haven for smaller 'productionist' niche market players. Although funds provided by the US Human and Health Services are significant for one single customer to put forward, it is a relatively small and volatile market compared with drugs for conventional diseases. It then falls to the eager but less experienced and smaller biotech companies (usually start-ups), dependent on public funding, to develop new MedCMs [25].

\section{Case of the Ebola Virus Disease Outbreak 2014}

Although a strategic planning workgroup of the US CDC identified EVD as a top 'Category A' biological threat in 2000 [2], development of a MedCM was not initially prioritized. The BioShield program was launched in 2004; however, its initial efforts to guard against CBRN terrorism focused on securing next-generation vaccines for anthrax and smallpox. While USA and a handful of other countries included the availability of MedCMs for both agents in their national stockpiles, the spread of EVD across Western Africa via a natural outbreak emerged in March 2014 as headline news, drawing into question the considerations used in assessing holistic CBRN threats and prioritizing funding for different MedCM. This section highlights the potential to strengthen the case to fund MedCMs for naturally occurring diseases with epidemic potential, which could impact Western armed forces operating in the area of the outbreak or travelers, who may transfer the disease back to their home countries.

Since the first known outbreak of EVD in 1976, there have been several natural outbreaks in Africa. Prior to 2014, Sudan, Uganda, Republic of Congo, and Gabon experienced reoccurrences, reporting a total of some 2000 cases and 1200 deaths. Despite the random nature and low incidence of EVD, with the highest number of cases caused by a single outbreak being 425 in Uganda in 2001 (Fig. 1), the latest EVD outbreak in Guinea showed that a MedCM had not been sufficiently fostered; a MedCM was not available. With unprecedented magnitude, that EVD outbreak has since claimed over 11,000 lives in the three most-affected countries of Guinea, Liberia, and Sierra Leone, as at February 2016 (Fig. 2). Among the 28,000 cases recorded, the rate of mortality was about $40 \%$ but varied according to the country (30\% in Sierra Leone, $43 \%$ in Liberia, and $64 \%$ in Guinea).

Although these official numbers are substantial compared with past outbreaks, the real figures remain uncertain, as many cases were not recorded because of the remote areas where they occurred and because victims died before treatment and registration. Nonetheless, that outbreak's dimension triggered the prioritization of innovative MedCMs against EVD [26]. As EVD re-emerged several times after 1976 in various countries, the effort to achieve a vaccine could have been considered as a global public good (GPG). Indeed, potential benefits would have extended across borders but a global government or organization does not exist to invest in such health-related GPGs [27]. Consequently, what exactly drove several members of the international community to attempt to achieve a vaccine during the 2014 outbreak? The response for medical intervention is examined before exploring the main reasons contributing to a lack of preparedness and then to a change of attitude.

\subsection{Response for Medical Intervention}

The strong response to the EVD threat included the formation of international consortia to accelerate the development of two vaccines. The first is co-developed by 
Fig. 1 Impact of natural Ebola virus disease outbreaks before March 2014 [28]

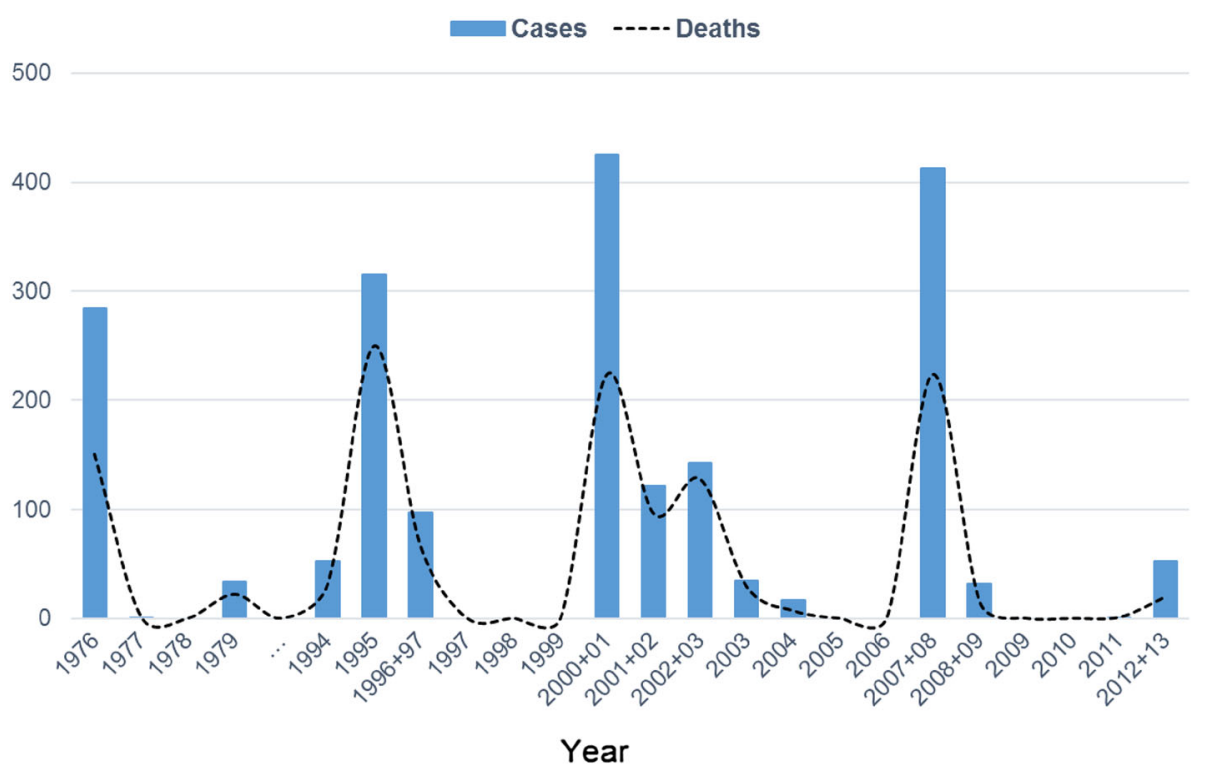

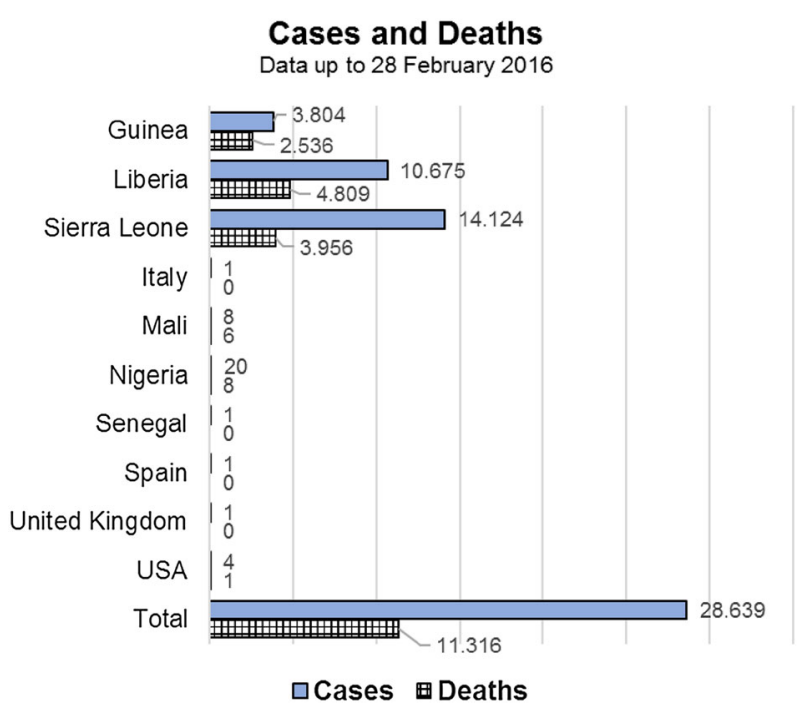

Fig. 2 Impact of Ebola virus disease deaths following the March 2014 outbreak [5]

GlaxoSmithKline and the US National Institutes of Health, the second by NewLink Genetics and researchers at the Public Health Agency of Canada. During the 2014 EVD outbreak, the experimental drug from Mapp Biopharmaceuticals known as ZMapp received substantial press coverage, but the ability to scale up supply in the short term was extremely limited and its efficacy unproven [29]. Since September 2014, Biomedical Advanced Research and Development Authority (BARDA) has provided funding and other technical support through a US\$24.9 million, 18-month contract with Mapp, extendable up to a total of US\$42.3 million [30].

This contract was the first BARDA program supporting the development of a MedCM against viruses that cause viral hemorrhagic fever (such as EVD). A year later,
BARDA's total investment for various EVD vaccines and therapeutics, manufacturing, diagnostics, and studies reached almost US\$215 million [31]. Interestingly, funding by company projects for vaccines and therapeutics, which totals roughly US\$176 million, reveals that some of these companies are large global pharmaceutical players (e.g., Merck, GlaxoSmithKline, Janssen), despite the fact that profitable scenarios similar to those offered for widespread conventional diseases remain highly unlikely (Table 1). Such participation might be motivated by their desire to positively position their reputation, or by a sense of patriotic duty during a time of emergency, as with the high dedication to vaccine development observed during World War II [32]. However, with the receding public attention to EVD and the continuing insufficient market demand, the sustainability of large company $R \& D$ initiatives is not ensured.

Empirical analysis [33] and events such as the 2001 US anthrax letter attacks and the 2014 EVD outbreak suggest that a high 'willingness to pay' for MedCMs materializes when risk perception is imminent and objective, or increases owing to emotional factors promoted by press coverage, or social media output, for example. However, to ensure a MedCM is available before a threat is imminent, the lengthy, risky, and expensive $R \& D$ process must be undertaken in the absence of such risk perception pressure. More generally, there is need for rational allocation of resources beyond political preferences [34].

During the peak of the EVD 2014 outbreak, there was international support to accelerate $R \& D$ initiatives to achieve new vaccines and therapeutics. It would indeed appear that significant R\&D advances have been made; however, semi-advanced MedCM candidates were already in the development pipeline at various stages. One of the 
Table 1 Biomedical Advanced Research and Development Authority (BARDA) investments in Ebola virus disease for vaccines and therapeutics [31]

\begin{tabular}{llll}
\hline & Company & Country of HQ registration & Funding (US\$ million) \\
\hline Vaccines & Merck and NewLink Genetics & Both USA & 49.8 \\
& GlaxoSmithKline & UK & 12.98 \\
& Janssen and Bavarian Nordic & Belgium/Denmark & 28.6 \\
Profectus BioSciences & USA & 5.9 \\
& & Total & 97.28 \\
Mapp Biopharmaceutical & USA & 19.9 \\
BioCryst Pharmaceuticals & USA & 17.8 \\
Regeneron & USA & 17.1 \\
CIADM (a BARDA center) and Genentech & Both USA & 19.8 \\
CIADM and DuPont & Both USA & 0.4 \\
Medicago & Canada & Germany & 1.8 \\
Fraunhofer & Total & 78.8 \\
\hline
\end{tabular}

CIADM Center for Innovation in Advanced Development and Manufacturing, $H Q$ headquarters

most advanced and promising vaccines, VSV-ZEBOV, licensed to Merck and NewLink Genetics, had already undergone animal trials in the early 2000s, under development by the Public Health Agency of Canada [35]. Funding and technical support by BARDA has proved invaluable to regulators, clinicians, and manufacturers, and improved the efficiency of the transfer of available data. However, a license has not yet been achieved for any EVD MedCM [36]. Since January 2015, the European Commission has provided $€ 215$ million to the Ebola + program of the Innovative Medicines Initiative to accelerate vaccine and diagnostic development. The Innovative Medicines Initiative is jointly sponsored by the European Commission's Horizon 2020 research program and the pharmaceutical industry [38].

Direct public funding and technical support have been complemented by incentive measures. In an attempt to further incentivize industry to develop MedCM against EVD, the US Food and Drug Administration granted ZMapp 'orphan drug' status in August 2014. Two months later, the European Medicines Agency offered developers of EVD treatments and vaccines the benefits of 'orphan drug' status. Receiving orphan drug status increases the value proposition to industry by providing free scientific advice, fee waivers, fast-track approval evaluation, extended market exclusivity, and even tax benefits [37].

The EVD outbreak also contributed to inspiring other outcomes, such as the Coalition for Epidemic Preparedness Innovations (CEPI) and the Pandemic Emergency Financing Facility (PEF). CEPI is an international non-profit association hosted by the Norwegian Institute of Public Health, with its start-up phase expected to run until the end of 2017. CEPI aims to achieve global consensus on new and sustainable partnership models required to achieve MedCM that can contain various emerging infectious diseases. To that end, founding members plan to fill financing gaps created by market failure by pooling and coordinating funds for associated R\&D, manufacturing capabilities, as well as the harmonization of effective regulatory requirements [38]. Initial investments of US\$540 million for this cause have been received internationally from governments and foundations [39]. The PEF initiative involves collaboration with the World Bank Group, the insurance industry, and capital markets. Its objective is to bridge the critical financing gap that begins in the early stages of an outbreak up to the point where the crisis level rallies further monetary support [40]. The PEF pay-outs are triggered when an outbreak meets pre-defined threshold values, such as the number of deaths or infections within a given timeframe [41]. Although the monetary basis for these pay-outs is provided via both insurance and cash, it also requires longterm pledges from development partners to pay insurance premiums and interest on catastrophe bonds. The purchase of this coverage in both the insurance and capital markets helps to lower the cost and increase the amount of coverage the PEF can obtain. To stimulate this mechanism, the private risk takers, bond investors, or insurance companies are paid a premium proportionate to the risk they are taking [42].

Similar to the PEF's partial use to support monetary pay-outs, it is conceivable that associations working to achieve global consensus for prioritized MedCMs (i.e., CEPI) may also find it beneficial to adapt contemporary principles from traditional insurance models. While 
insurance protection potentially benefits everyone because its funding comes from shared and reasonable contributions to mitigate the financial risk of specified threats, core competencies of insurance companies include the coordination of sufficient membership to secure substantial 'pay out' capability. Hence, to fill financing gaps created by market failure, an international non-profit association able to achieve global consensus for prioritized MedCMs could propose an alternative form of insurance to multiple governments worldwide. Instead of making monetary pay-outs available upon a specified disease outbreak, as with the insurance component of the PEF initiative, $R \& D$ progress and eventually the availability of MedCMs against prioritized naturally occurring diseases that can also be weaponized and intentionally released could be offered.

Upon considering the US CDC's 'Category A Biological Threats,' this could include examples such as anthrax, plague, smallpox, tularemia, and viral hemorrhagic fevers, such as EVD. Targeting such diseases would render the larger international community as a potential policy holder because all or most are susceptible to bioterrorism. This is likely not the case when only rare or potentially emerging diseases are considered. If a high number of insurance policy holders could be achieved, insurance premium rates would most certainly be far lower and much more sustainable than when emergency measures for MedCM are dependent only on a handful of voluntary donors. Moreover, the establishment of such an insurance mechanism may potentially even align the missions of different government agencies and philanthropic organizations focused on CBRN MedCMs and global health concerns, thus, possibly setting the stage to enable a more global and mandatory insurance coverage requirement.

\subsection{Contributors to Lack of Preparedness}

To understand the factors that led to a quasi-laissez-faire attitude towards EVD as a natural outbreak, it is important to put the threat into perspective. On a global scale (or even just for Africa), many widespread diseases cause far greater fatality rates, according to the WHO (including pneumonia, human immunodeficiency virus, malaria, diarrhea, tuberculosis). In fact, for many of these diseases, more economically developed countries (MEDC) are already trying to improve Africa's medical management programs.

For example, roughly 3.2 billion people remain at risk of malaria. For 2015 alone, the 214 million new cases reported have caused 438,000 deaths. Approximately 80\% of deaths are concentrated in just 15 countries, mainly in Africa, and millions of people are still not able to access health services to prevent or treat malaria. Even if the international community could have supported early EVD MedCM programs, granting them financial priority against other programs aimed at meeting basic medical needs would have remained a challenge. While the treatment of infected patients during an epidemic presents a great medical challenge, the improvement of healthcare systems alone could significantly contribute to its containment via increased technical and allocative efficiencies [34]. Correspondingly, the next EVD outbreak could be effectively managed by assuming appropriate conditions and effective isolation of patients [43].

As described, the current economic tools and metrics applied to allocating funding resources did not facilitate MedCM development against EVD prior to the 2014 outbreak. To quantify the burden of disease from mortality and morbidity, the WHO applies a metric known as the disability-adjusted life-year (DALY). One DALY can be thought of as one lost year of healthy life, obtained by adding the adjusted number of years lived with a disability (YLDs $=$ number of cases $\times$ duration till remission or death $\times$ disability weight) to the number of years of life lost because of premature mortality (YLLs $=$ number of deaths $\times$ life expectancy at the age of death).

Based on total DALYs, the top four leading causes of disease burden in Africa are ranked in Table 2. Compared with their ranking in Africa, in other regions such as the Americas and Europe these diseases are clearly far less prominent in terms of their relative cost in DALYs and deaths (Table 3). The total DALY share of these diseases reaches $\sim 27 \%$ for less economically developed countries but represents less than 13\% for MEDC with roughly $20 \%$ and less than $8 \%$ of the share of deaths, respectively.

Disability-adjusted life-years may be used to evaluate health policies, compare intervention alternatives, and assess risk factors. When evaluating cost effectiveness, the WHO's threshold values for intervention are defined as very cost effective if the cost per DALY averted is less than the gross domestic product (GDP) per capita. It then becomes less and less cost effective the more that investment exceeds GDP per capita; an investment is no longer considered cost effective once it is exceeded by a factor of three [44].

Although the use of DALYs for policy making has been widespread since it was presented in the World Bank's 'World Development Report 1993,' it remains subject to criticism. Examples of flaws identified that could impede the application of DALYs to measure the burden of disease, or prioritize medical intervention, include the use of a theoretical maximum age, inaccurate disability weights, and ethically questionable principles [45] as well as a lack of transparency [46]. It is further argued that, in some cases, improvement could be gained by using relevant cohort life expectancies, local life tables, or a population model instead of the standard expected years of life lost method. Nonetheless, DALYs in their current state heavily 
Table 2 Top ranking causes of disease burden in Africa and their relative ranking in other regions, based on disability-adjusted life-years [47]

\begin{tabular}{|c|c|c|c|c|c|c|c|}
\hline & Africa & Americas & South-east Asia & European & Eastern Mediterranean & Western Pacific & Global \\
\hline Lower respiratory infections & 1 & 9 & 1 & 14 & 1 & 10 & 1 \\
\hline HIV/AIDS & 2 & 19 & 15 & 16 & & & 6 \\
\hline Diarrheal diseases & 3 & & 3 & & 3 & & 4 \\
\hline Malaria & 4 & & & & & & 13 \\
\hline
\end{tabular}

Table 3 Relative comparison of disease burden [48]. Source: Institute for Health Metrics and Evaluation, Global Burden of Disease (2010)

\begin{tabular}{|c|c|c|c|c|c|c|}
\hline \multirow[t]{2}{*}{ Infectious diseases } & \multicolumn{3}{|c|}{ Share of DALYs } & \multicolumn{3}{|c|}{ Share of deaths } \\
\hline & Global & Developing & Developed & Global & Developing & Developed \\
\hline Diarrhea, lower respiratory infections, and other common infectious & 11.4 & 13 & 2.5 & 10 & 12 & 4 \\
\hline HIV/AIDS and tuberculosis & 5.3 & 6 & 1.7 & 5 & 6.3 & 1.1 \\
\hline Neglected tropical diseases and malaria & 4.4 & 5.2 & 0.1 & 2.5 & 3.3 & 0.03 \\
\hline Other & 24.9 & 27.2 & 12.6 & 17.1 & 19.9 & 7.37 \\
\hline
\end{tabular}

AIDS acquired immune deficiency syndrome, DALYs disability-adjusted life-years, $H I V$ human immunodeficiency virus

influence the amount of money donors are willing to invest in medical intervention.

Considering its application for determining investment against EVD, it remains that even 11,000 deaths are low compared with other major diseases and, thus, the number of DALYs is low. In sharp contrast, the WHO reports that worldwide annual epidemics of influenza are estimated to result in three to five million cases of severe illness, with about 250,000-500,000 deaths. Besides the influence of low incidence (thus, DALYs) to restrict funding against EVD, the cost-effectiveness calculation benchmarks GDP per capita in the African countries affected and this, too, is particularly low. Indeed, GDP per capita in those countries (Congo, Guinea, Liberia, Sierra Leone, and Sudan) ranged between roughly US\$440 and US\$1900 in 2014 (Fig. 3). This compares to a GDP per capita in MEDC recently experiencing a few EVD cases (e.g., USA, UK, Spain, Italy) ranging from US\$30,000 to US\$55,000. To avoid placing a substantially lower value on human life in less economically developed countries by using DALYs, it is argued that if a cost-effectiveness threshold of US\$10,000 per DALY averted were applied, at least US\$1.25 billion for the development of a vaccine against EVD could have been considered cost effective [49]. Indeed, contrary to such cost-effectiveness thresholds that are directly dependent on GDP per capita, setting a global baseline costeffectiveness value could enhance transparency and fairness because it would enable cross-country comparisons and represent a universal minimum value on human health [50].

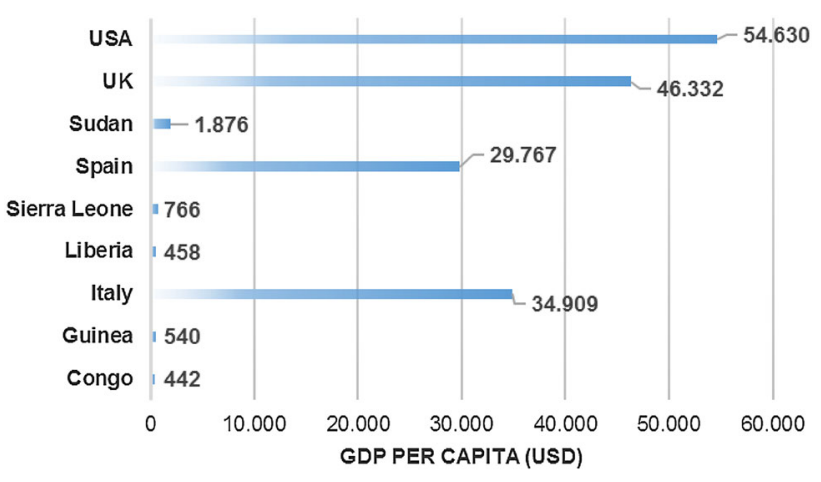

Fig. 3 Gross domestic product (GDP) per capita in 2014 for countries often hit by Ebola virus disease [51]. USD US dollars

\subsection{Reasons to Act}

Given that the lack of a MedCM contributed to EVD's spread, the various costs due to its absence have to be assessed. Although routine cost-effectiveness modeling may have contributed to inaction, new awareness appears to have sparked the initiation of urgent MedCM projects as previously outlined. With both the GDP per capita in the affected African countries and the incidence still comparatively low, what are the main drivers of change? The main economic one seems to be the realization that failing to respond in time could have severe consequences, including financial ones. For instance, if US\$100 million had been made available in early summer of 2014, instead of the autumn when the crisis had already skyrocketed, the tenfold increase in EVD cases would have been avoided [40]. 
Early surge funding would not only have prevented deaths, but would have saved billions of US dollars. In other words, there is a cost of inaction and a growing awareness about it. Thus, accepting the high costs of medical intervention and MedCM development became more attractive than ignoring the EVD threat. Correspondingly, as the spread of EVD outpaced the response, more forceful international support was summoned by the United Nations Security Council in September 2014, embodied by the adopting of Resolution 2177. This called on United Nations countries to urgently respond to the crisis and refrain from isolating the affected countries [52]. Only shortly thereafter, by the end of September 2014, EVD cases began to surface in MEDC, including Spain and USA. While the 'unprecedented extent' of the outbreak was perceived to constitute a threat to international peace and security, it is plausible that several countries also viewed the unique adverse impact the EVD could pose within its own borders. Three key drivers emerged that possibly encouraged the robust initiation of MedCM development: the disease's political and geostrategic implications, its social disruption and emotional factors affecting GDP, and a positive ROI.

Whilst the DALY approach may be useful in a costeffectiveness perspective, it does not consider political and geostrategic implications. Yet, these concerns were raised by the United Nations during its deliberations over whether to engage its member states' resources to help control the spread of EVD. It was argued that if EVD was allowed to continue its spread across Guinea, Liberia, and Sierra Leone and perhaps neighboring regions, the social and economic structures of these countries could weaken further, with the resulting havoc and instability threatening their governments. To illustrate its impact in the countries most afflicted, it has been shown that at the peak of the 2014 outbreak, EVD was actually the leading cause of death in Liberia and possibly even in Sierra Leone, while in Guinea it was the third leading cause of death [26]. Given the valuable natural resources in some of these countries, there was a fear of rising terrorism and that these resources would fall under the control of radical groups. For example, Guinea is one of West Africa's most mineral-rich countries and, despite its economy in ruins, has the world's largest reserves of bauxite and some of the highest grade iron ore deposits [53]. Another example is Nigeria, which suffered at least 20 cases of EVD during the 2014 outbreak. With crude oil production of $\sim 1000$ barrels per day, the oil and gas sector accounts for almost $35 \%$ of its GDP and more than $90 \%$ of total exports [54]. Because the EVD outbreak could be deemed a likely destabilizing factor for the countries hit, only a strong response against the virus could mitigate severe economic turmoil associated with disruption of the supply and procurement of natural resources.
A paramount trigger behind the united effort against the spread of EVD was the growing awareness that the virus could be exported to MEDC, resulting in adverse economic and social consequences. This spread would not only have led to a higher outbreak incidence (thus, increased DALYs) but would have also significantly raised funding levels for medical intervention because the DALY metric benchmarks GDP per capita of countries that would have been hit. With this being significantly higher in MEDC, higher investments can be determined as cost effective. Of course, it can be argued that the robustness of healthcare infrastructure in MEDC would be capable of quickly containing any imported EVD case. However, the effectiveness of non-medical containment measures is dependent on the establishment of trust in government, if associated government-mandated social distancing mechanisms are to be abided by the potentially exposed population [55]. Assuming so, the ability of the cost-effectiveness model to increase investment would not be realistic because there would not be a significant change to the incidence. Nonetheless, the fear alone of being exposed to the EVD might have a negative impact on GDP in MEDC and others.

In October 2014, it was estimated that EVD could potentially cause up to US $\$ 33$ billion in losses for West Africa's economy [56]. Such economic damage would have been induced by the lower output as a result of changed behavior in various economic sectors (e.g., workers/farmers failing to show up for work, shop owners closing their stores, exodus of foreign professionals in key positions in the economy, reduced tourism). However, thanks to international efforts to improve the treatment capabilities of the affected countries, this economic loss was subsequently estimated at US $\$ 1.6$ billion. This still represented over $12 \%$ of their combined GDP. Besides the economic damage caused in countries hit by EVD, an additional loss of US $\$ 0.5$ billion was estimated for a swath of countries stretching from Gambia through Kenya to South Africa, as a result of the impact on their tourism. Adding the two losses makes a total loss of US $\$ 2.1$ billion for the African region [57]. As the EVD crisis receded, GDP growth rebounded somewhat in Liberia, but remained weak in Guinea and Sierra Leone (Fig. 4). However, in Sierra Leone, the fall in GDP by $20 \%$ in 2015 was not exclusively owing to the EVD outbreak but to delays in starting up an iron ore mining project plus a concomitant drop in global iron ore prices by 50\% [58]. Ultimately, a loss in growth of 5\% was attributed to the EVD outbreak for each of the three countries in 2014, causing a total loss estimated at US $\$ 2.2$ billion [59, 60].

Ebola virus disease threatened not only West Africa's economic stability via lower investment and a substantial loss in private sector growth, but also a decline in 
Fig. 4 Real gross domestic product (GDP) growth rates [58]

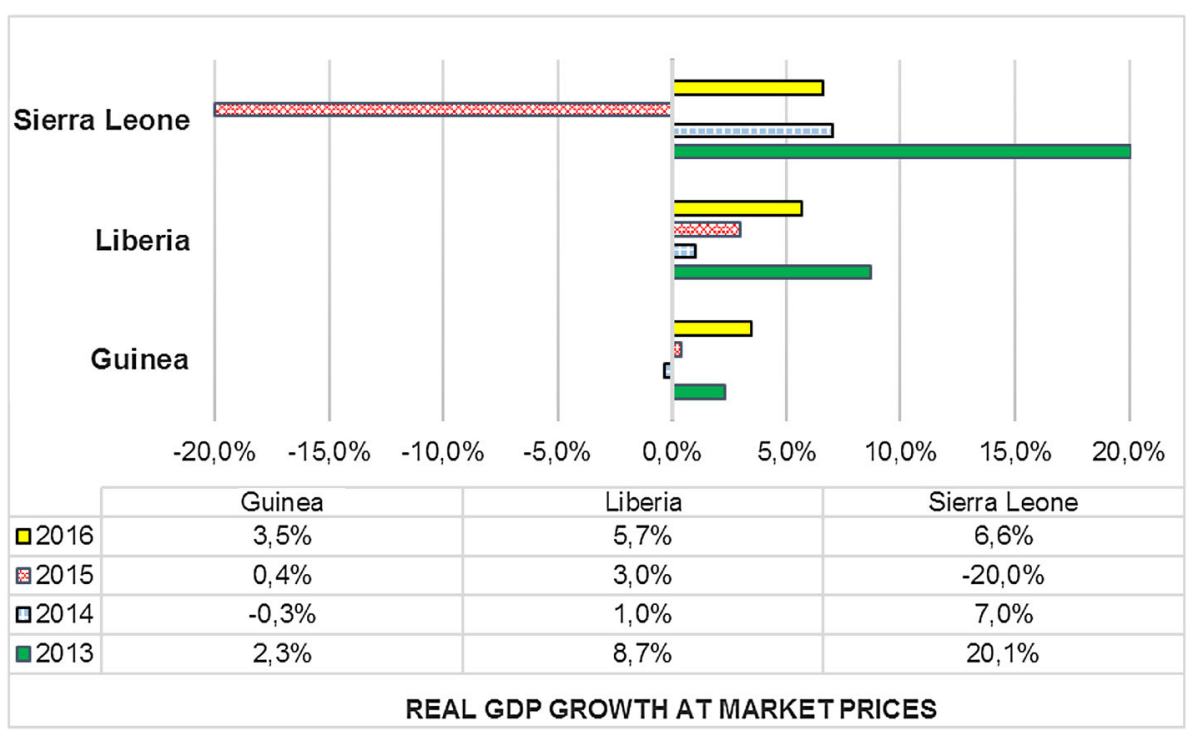

agricultural production. The latter triggered concerns about food security and a decrease in cross-border trade as restrictions on the movement of people, goods, and services increased. The contrast with the possible impact on MEDC is striking. The combined total GDP in 2014 of the MEDC that experienced an EVD case-USA, UK, Italy, and Spain-equals almost US\$24 trillion. Even if only a fraction of the EVD fear as a result of further incidence and delayed containment were to have reached these four MEDC, a negative impact of just $1 \%$ to their combined GDP would have incurred an overall loss of over US $\$ 200$ billion.

The last key driver that can explain the decision to invest in MedCMs against EVD is based on economic grounds to reduce direct costs, aside from the role and interests of governments to protect the health of their populations and their economies. Return on investment calculations for previous vaccination projects may provide supportive guidance on this issue. For example, the costs of the WHO's enormous smallpox eradication program during 1967-1979 totaled US\$300 million, but these have been 'repaid' many times over in the human lives saved and the averted costs for vaccines, treatment, and international surveillance post-eradication. Those savings are estimated at more than US $\$ 2$ billion each year [61]. Since smallpox's eradication in 1980, USA has recouped nearly 500-fold the value of its contribution to that effort [62]. While the considerable ROI achieved by eradicating smallpox does not necessarily apply directly to EVD, which has a higher mortality rate but is less contagious, it does demonstrate that its substantial savings potential may have been underestimated. Although the definition of costs remains not entirely clear, the cost of fighting EVD was estimated at more than US $\$ 3.6$ billion by the end of 2015
[59]. The top donators are the US Government, UK, Germany, and the World Bank Group. In addition to providing personnel, technical expertise, and resources, these funds have been used to establish three new emergency operation centers in Guinea, Liberia, and Sierra Leone.

As early as September 2014, the United Nations predicted it would need nearly US\$1 billion to help fight EVD outbreak in West Africa. These funds were required not only for MedCMs, but for a series of measures ranging from compensation for health workers and the purchase of supplies to the tracing of people exposed to the virus. Roughly US\$23.8 million was needed just to pay burial teams and buy body bags because the corpses of EVD victims are highly infectious, requiring protective gear for workers [63]. In its attempt to end the epidemic in West Africa and to strengthen its own domestic preparedness against EVD, USA passed legislation on February 2015 that included US\$5.4 billion in emergency funding [64]. The above-mentioned estimate of more than US $\$ 3.6$ billion already represented an unprecedented high cost to fight a single EVD outbreak. Yet, the impact of EVD could have been far easier, quicker, and less costly to contain if a MedCM had been available. Thus, a clear argument surfaces supporting investment in new MedCMs against EVD.

On the other side, it is clear that the cost of inactionrestraining the response and medical intervention effortswould have been far greater. For instance, despite the intensity of response, the three hardest hit countries were required to put EVD recovery plans in place. This maps out strategies for responding to the epidemic's human and economic damage. The projected price tags are substantial: US\$812 million for Liberia, US\$844 million for Sierra Leone, and US\$2.89 billion for Guinea [65]. As discussed previously, out-of-pocket costs to develop a MedCM of 
this nature can reach roughly US $\$ 1.5$ billion. Thus, when considering ROI, it is plausible that at least a break-even point would have been achievable, based solely on this single outbreak event. As the availability of a MedCM should also substantially decrease the impact of future outbreaks (or even prevent them), it would appear that a strong business case with an attractive ROI could be prepared for relevant financial donors.

\section{Conclusion}

Given limitations on the sources of funding, and thus the need to set priorities, it quickly becomes clear that a holistic blanket of protection with MedCMs against all CBRN agents cannot be an option. A warranted array of medical intervention programs will inevitably continue to compete for finite time, financial resources, and diverse interests. For diseases causing high prevalence and incidence, mainstream industry will continue to develop and provide innovative medical solutions within the context of free market forces. The high market sales potential induced is best compatible with the growth objectives of their financialized business models. This is not the case for several highly dangerous but naturally rare CBRN agents. Even taking the latest unprecedented outbreak into account, the historical and unpredictable impact of EVD on disability and life stands little chance of leading to a blockbuster vaccine. Hence, while mainstream industry may view its own potential profitability as an opportunity cost, governments have to protect their populations and in some cases, their economic stability. Because of the nature of the R\&D processes necessary to develop new MedCM, governments are challenged to set timely and appropriate priorities. Despite current decision metrics that guide disease categories and the funding levels that governments and donors are willing to provide for that aim, the lack of MedCM preparedness for the last EVD outbreak suggests there is room for improvement.

As illustrated, the EVD threat may have been easy to ignore because of its perceived lack of magnitude and geographical reach but it ultimately imposed a sharing of the costs of response of many countries. Given that an EVD outbreak can occur naturally and impact Western armed forces operating in the area of the outbreak or travelers who may transfer the disease back to their home countries, it serves to demonstrate benefits of aligning the missions of different government agencies and international non-profit associations focused on CBRN MedCMs and global health concerns. If a cost-benefit analysis may help to allocate resources in a timely manner to achieve sustainable development of MedCMs against rare CBRN agents, the international community —at least those countries sharing a vested interest to mitigate their risks-should agree on priority metrics capable of capturing their unique threat characteristics. Indeed, the EVD case demonstrates that direct costs of emergency response and interconnection between political, economic, and emotional factors that may affect GDP should not be ignored. Whilst tremendous foresight will be required of the international community to prioritize and incentivize the availability of MedCMs against rare threats, their investments must aim to strike a better balance between offering public procurement contracts more equal to conventional market reward levels and $R \& D$ funding. Otherwise, it is not profitable for businesses to develop a MedCM and wait for events of low prevalence and/or probability to occur. Sustainable public intervention is needed to cope with market failure by providing new sources of timely financing and/or incentives to create more favorable market conditions, as with orphan drug status. Additionally, because of substantial costs and financial constraints, appropriate research is needed, along with medical and industrial infrastructure.

Finally, alternative approaches to evaluating the 'real' threat of specific CBRN agents to international security and peace need to be developed. Governments must understand that everyone is worse off if there are no cooperative efforts to fund effective MedCMs against some CBRN agents. While governments can, in theory, finance public goods by means of taxes or licensing, many countries lack the resources to deal with the more acute but basic public health needs. Because CBRN exposure is likely to extend across borders through travel, policy makers should not recede into wait-and-see or free-rider behavior hoping for others to fund a MedCM they will benefit from. On the contrary, there is a need for international cooperation at the state level (or even via management GPGs), especially when less economically developed countries are hit by CBRN events. Given the high sensitivity of using DALYs to GDP inequalities between countries, this would imply the creation of a platform for determining appropriate metrics to assess cost effectiveness.

A more careful prioritization of MedCM development and availability can be viewed as a sort of international health insurance policy: protection for human and economic health irrespective of whether the event occurs in a particular country or not. Should global consensus for prioritized MedCM be achieved by an international nonprofit association, it is plausible that the adaption of an insurance model could help to fill financing gaps created by market failure. Namely, insurance pay-outs to global policy holders upon outbreak of specified naturally occurring diseases that can also be weaponized (or intentionally released) could be fulfilled by the provision of associated R\&D progress and eventually the availability of MedCM. Other post-EVD outbreak initiatives such as the World 
Bank Group's PEF involve collaboration with profit-driven sectors (the insurance industry, and capital market proceeds from catastrophe bonds). Hence, their individual missions may even share joint interest to establish R\&D progress and availability of MedCM against mutually targeted diseases. For example, it is likely that medical response readiness could reduce pay-outs required under the PEF's mission to bridge the critical financing gap that begins in the early stages of an outbreak. Moreover, the profit-driven sector may even choose to proactively drive risk mitigation initiatives to retain and maximize its own financial platform (e.g., by supporting preparedness of MedCM). Thus, the creation of an alternative managing mechanism for developing and procuring GPGs such as MedCM against particular CBRN agents could emerge. Although this concept may not apply to all biological agents identified under the CBRN term, further economic and governance analysis should be performed to determine various costeffective and feasible case scenarios to encourage global protection wherever this can be rationally achieved.

Acknowledgements The authors thank V.G. Johnson from Regulatory Science, LLC, and X. Tong from Smart Consulting Group, LLC, for providing research and development assessments of chemical, biological, radiological, and nuclear medical countermeasures, S.V. Reeves Major General, USA (Ret) for providing US military research and development cost estimates, and C.H. Sorensen, Director-General of the European Commission's Humanitarian Aid and Civil Protection (ECHO), for his political and geostrategic comments regarding the Ebola virus disease response. The authors also thank Brooks Tigner from Security Europe for his prior edits as well as Cameron Wright, the editor of Pharmaceutical Medicine, and two anonymous referees for their helpful comments.

\section{Compliance with Ethical Standards}

Funding No financial support was received for the preparation of this article.

Conflict of interest Mark Lawrence Johnson, Jean Belin, Frederic Dorandeu, and Marianne Guille have no conflicts of interest directly relevant to the content of this article.

\section{References}

1. GHSI. 16th Ministerial Meeting. Washington, DC; 2016.

2. US CDC. Biological and chemical terrorism: strategic plan for preparedness and response. 49 (RR04); 1-14. Atlanta (GA); 2000. Available from: https://www.cdc.gov/Mmwr/PDF/rr/ rr4904.pdf. Accessed 23 Oct 2017.

3. Stroud C, Nadig L, Altevogt BM. Medical countermeasures dispensing: emergency use authorization and the postal model. Washington: National Academy of Sciences; 2010.

4. Pammolli F, Magazzini L, Riccaboni M. The productivity crisis in pharmaceutical R\&D. Nat Rev Drug Discov. 2011;10:428-38. Available from: http://dx.doi.org/10.1038/nrd3405. Accessed 23 Oct 2017.

5. WHO. Ebola situation reports. 2016. Available from: http://apps. who.int/ebola/ebola-situation-reports. Accessed 6 Mar 2016.
6. EMA. Orphan designation. 2016. Available from: http://www. ema.europa.eu/ema/index.jsp?curl=pages/regulation/general/gen eral_content_000029.jsp. Accessed 15 Mar 2015.

7. PhRMA. Drug discovery and development: understanding the R\&D process. Washington, DC; 2007. Accessed 15 Mar 2016. Available from: http://cmidd.northwestern.edu/files/2015/10/ Drug_RD_Brochure-12e7vs6.pdf. Accessed 15 Mar 2016.

8. Robinson RA. BARDA today and tomorrow: goals, priorities, successes and challenges. BARDA Ind. Day Conf. 2015. Washington, DC: United States Department of Health and Human Services Office of the Assistant Secretary for Preparedness and Response; 2015. Available from: http://www.medicalcountermeasures.gov/media/ 36851/01_robinson_barda_today_tomorrowetc.pdf. Accessed.

9. DiMasi JA, Grabowski HG, Hansen RW. Innovation in the pharmaceutical industry: new estimates of R\&D costs. J Health Econ. 2016;47:20-33.

10. Hall BH. The financing of research and development. Oxford Rev Econ Policy. 2002;18:35-51.

11. Belin J, Guille M. Defence and firm financial structure in France. Rev Financ Econ. 2008;17:46-61.

12. Wizemann T, Stroud C, Altevogt BM. The public health emergency medical countermeasures enterprise: innovative strategies to enhance products from discovery through approval: workshop summary. Washington, DC; 2010. Available from: http://www. nap.edu/catalog/12856.html. Accessed 23 Oct 2017.

13. EC. Risk management. 2016. Available from: http://ec.europa.eu/ health/preparedness_response/risk_management/index_en.htm. Accessed 26 May 2016.

14. Russell PK. Project BioShield: what it is, why it is needed, and its accomplishments so far. Clin Infect Dis. 2007;45:68-72.

15. Gronvall G. Biodefense countermeasures: the impact of Title IV of the US pandemic and all-Hazards preparedness act. Emerg Health Threats J. 2008;1:1-5.

16. PHEMCE. Public Health Emergency Medical Countermeasures Enterprise (PHEMCE) strategy and implementation plan. USA: U.S. Department of Health and Human Services, Washington, DC; 2014.

17. Gottron F. The project BioShield Act: issues for the 113th Congress. Congr Res Serv. 2014.

18. Mazzucato M, Tancioni M. R\&D, patents and stock return volatility. J Evol Econ. 2012;22:811-32.

19. Walsh G. Biopharmaceutical benchmarks 2014. Nat Biotechnol. 2014;32:992-1000.

20. Aitken M, Kleinrock M, Lyle J, Nass D, Caskey L. Global outlook for medicines through 2018. Available from: http://www.imshealth. com/en/thought-leadership/quintilesims-institute/reports/globaloutlook-for-medicines-through-2018. Accessed 23 Oct 2017.

21. Gleadle P, Parris S, Shipman A, Simonetti R. Restructuring and innovation in pharmaceuticals and biotechs: the impact of financialisation. Crit Perspect Account. 2014;25:67-77.

22. Shimura H, Masuda S, Kimura H. Research and development productivity map: visualization of industry status. J Clin Pharm Ther. 2014;39:175-80.

23. Andersson T, Gleadle P, Haslam C, Tsitsianis N. Bio-pharma: a financialized business model. Crit Perspect Account. 2010;21:631-41.

24. Lazonick W, Tulum Ö. US biopharmaceutical finance and the sustainability of the biotech business model. Res Policy. 2011;40:1170-87.

25. Maher C, Hu-Primmer J, Macgill T, Courtney B, Borio L. Meeting the challenges of medical countermeasure development. Microb Biotechnol. 2012;5:588-93.

26. Helleringer S, Noymer A. Magnitude of ebola relative to other causes of death in Liberia, Sierra Leone, and Guinea. Lancet Glob Health. 2015;3:255-6.

27. Smith RD. Global public goods and health: concepts and issues. Bull World Health Organ. 2003;81:1. 
28. US CDC. Outbreaks chronology: Ebola virus disease. 2016. Available from: http://www.cdc.gov/vhf/ebola/outbreaks/history/ chronology.html. Accessed 6 Mar 2016.

29. Tully CM, Lambe T, Gilbert SC, Hill AV. Emergency Ebola response: a new approach to the rapid design and development of vaccines against emerging diseases. Lancet Infect Dis. 2015;15(3):356-9.

30. US HHS. HHS contracts with Mapp Biopharmaceutical to develop Ebola drug. 2014. Available from: http://www.hhs.gov/ news/press/2014pres/09/20140902b.html. Accessed 13 Feb 2016.

31. Disbrow GL. Ebola update. BARDA Ind. Day Conf. 2015. Washington, DC: United States Department of Health \& Human Services Office of the Assistant Secretary for Preparedness and Response; 2015. Available from: https://www.medicalcountermea sures.gov/media/36841/17_disbrow_ebola-update.pdf. Accessed 14 Sept 2017.

32. Hoyt KL. Long shot: vaccines for national defense. Cambridge: Harvard University Press; 2012.

33. Travisi CM, Nijkamp P, Vindigni G. Pesticide risk valuation in empirical economics: a comparative approach. Ecol Econ. 2006;56:455-74.

34. Flessa S, Marx M. Ebola fever epidemic 2014: a call for sustainable health and development policies. Eur J Health Econ. 2015;17:1-4.

35. Stoye E. Vaccine raises hopes of an end to Ebola. August 2015. Available from: http://www.rsc.org/chemistryworld/2015/08/ vaccine-vsv-zebov-raises-hope-end-ebola. Accessed 17 Oct 2017.

36. US HHS. 2015 Public Health Emergency Medical Countermeasures Enterprise (PHEMCE) strategy and implementation plan. Washington DC; 2015. Available from: http://www.phe.gov/ Preparedness $/ \mathrm{mcm} /$ phemce/Documents/2015-PHEMCE-SIP.pdf. Accessed 23 Oct 2017.

37. Wellman-Labadie O, Zhou Y. The US Orphan Drug Act: rare disease research stimulator or commercial opportunity? Health Policy. 2010;95:216-28.

38. CEPI. Coalition for Epidemic Preparedness Innovations (CEPI) preliminary business plan. Oslo; 2017. Available from: http:// www.who.int/medicines/ebola-treatment/TheCoalitionEpidemic PreparednessInnovations-an-overview.pdf. Accessed 23 Sept 2017.

39. CEPI. CEPI: new vaccines for a safer world. Oslo, 2017. Available from: http://cepi.net/sites/default/files/CEPI_2pager_ 27_Apr_17.pdf. Accessed 23 Sept 2017.

40. The World Bank. Pandemic emergency facility: frequently asked questions. World Bank; 2016. Available from: http://www. worldbank.org/en/topic/pandemics/brief/pandemic-emergencyfacility-frequently-asked-questions. Accessed 25 Feb 2017.

41. Estrada R, Griffith A, Prim C, Sinn J. Pandemics in a changing climate-evolving risk and the global response. Swiss Reinsurance Company Ltd., Zurich, Switzerland; 2016.

42. The World Bank. Pandemic emergency financing facility: global response through a financial intermediary fund. The World Bank: Washington, DC; 2016.

43. Khan A, Naveed M, Dur-E-Ahmad M, Imran M. Estimating the basic reproductive ratio for the Ebola outbreak in Liberia and Sierra Leone. Infect Dis Poverty. 2015;4:13.

44. WHO. Cost effectiveness and strategic planning (WHOCHOICE). 2016. Available from: http://www.who.int/choice/ costs/CER_levels/en/. Accessed 13 Feb 2016.

45. Lyttkens $\mathrm{CH}$. Time to disable DALYs? On the use of disabilityadjusted life years in health policy. Eur $\mathrm{J}$ Health Econ. 2003;4:195-202.
46. Fox-Rushby JA, Hanson K. Calculating and presenting disability adjusted life years (DALYs) in cost-effectiveness analysis. Health Policy Plan. 2001;16:326-31.

47. WHO. The health of the people: what works: the African Regional Health Report 2014. Republic of Congo: World Health Organization - Regional Office for Africa, Brazzaville; 2014.

48. Bloom DE. The shape of global health. Finance Dev. 2014;6-11.

49. Barder O. Finding a cure for Ebola. 2014. Available from: http:// www.cgdev.org/blog/finding-cure-ebola. Accessed 13 Feb 2016.

50. Drake T. Priority setting in global health: towards a minimum DALY value. Health Econ. 2014;23:248-52.

51. The World Bank. GDP per capita (current US\$). 2014. Available from: http://data.worldbank.org/indicator/NY.GDP.PCAP.CD. Accessed 14 Mar 2016.

52. United Nations. With spread of Ebola outpacing response, Security Council adopts resolution 2177. 2014. Available from: http://www.un.org/press/en/2014/sc11566.doc.htm. Accessed 14 Feb 2016.

53. Condé A. In Guinea we want our resource wealth to work for all the people. 2013. Available from: http://www.theguardian.com/ global-development/poverty-matters/2013/jun/14/guinea-resourcewealth-work-people. Accessed 15 Sept 2015.

54. OPEC. Nigeria facts and figures. 2015. Available from: http:// www.opec.org/opec_web/en/about_us/167.htm. Accessed 8 Mar 2016.

55. Blair RA, Morse BS, Tsai LL. Public health and public trust: survey evidence from the Ebola virus disease epidemic in Liberia. Soc Sci Med. 2017;172:89-97.

56. The World Bank. World Bank warns of economic threat to West Africa from Ebola crisis. 2014. Available from: http://www. worldbank.org/en/news/press-release/2014/10/08/ebola-new-world -bank-group-study-forecasts-billions-in-economic-loss-if-epidemic -lasts-longer-spreads-in-west-africa. Accessed 15 Sep 2015.

57. Thomas MR. Estimating the economic cost of Ebola. 2015. Available from: http://blogs.worldbank.org/developmenttalk/ estimating-economic-cost-ebola. Accessed 15 Jan 2016.

58. World Bank Group. Global economic prospects: spillovers amid weak growth. Washington, DC: International Bank for Reconstruction and Development/The World Bank; 2016.

59. US CDC. Cost of the Ebola epidemic. Atlanta (GA); 2016. Available from: http://www.cdc.gov/vhf/ebola/pdf/cost-ebolainfographic.pdf. Accessed 23 Oct 2017.

60. The World Bank. World Bank Group Ebola response fact sheet. 2016. Available from: http://www.worldbank.org/en/topic/health/ brief/world-bank-group-ebola-fact-sheet. Accessed 14 Feb 2016.

61. Ehreth J. The global value of vaccination. Vaccine. 2003;21:596-600.

62. Kenny C. The economic case for wiping out Ebola. Bloomberg; 2014. Available from: http://www.bloomberg.com/bw/articles/ 2014-08-25/the-economic-case-for-wiping-out-ebola. Accessed 14 Feb 2016.

63. United Nations. Ebola virus disease outbreak: overview of needs and requirements. Geneva; 2014. Available from: http://docs.unocha. org/sites/dms/CAP/Ebola_outbreak_Sep_2014.pdf. Accessed 23 Oct 2017.

64. US White House. Fact sheet: progress in our Ebola response at home and abroad. 2015. Available from: http://www.whitehouse. gov/the-press-office/2015/02/11/fact-sheet-progress-our-ebola-res ponse-home-and-abroad. Accessed 14 Feb 2016.

65. Mullan Z. The cost of Ebola. Lancet Glob Health. 2015;3:e423. 